\title{
Tetraplatinated Artificial Oligopeptides Afford High Affinity Intercalation into dsDNA
}

Lauren A. Levine, Christopher M. Morgan, Kristi Ohr, and Mary Elizabeth Williams*

Department of Chemistry, The Pennsylvania State University, 104 Chemistry Building, University Park, PA 16802

\section{Experimental}

\section{Chemicals and Materials.}

All materials were purchased from Acros and were used as received unless otherwise noted. Water was obtained from a nanopure system (Barnstead, 18.2 M $\Omega$ ). Single strand DNA oligomers (sequences 5'CAG CTG GTC ACG3' and 5'CGT GAC CAG CTG3') were purchased from Integrated DNA Technologies Inc with standard desalting. The pyridine substituted aeg monomer (Fmoc-aeg(py)$\mathrm{OH} \cdot \mathrm{HCl})$ was synthesized as reported previously. ${ }^{\mathrm{S} 1}$ The synthesis of $\left(2,2^{\prime}: 6^{\prime}, 2^{\prime \prime}\right.$-terpyridine- $\mathrm{N}, \mathrm{N}$ ', N")platinum (II) diperchlorate (i.e., $[\mathrm{Pt}(\mathrm{tpy})]^{2+}$ ) was adapted from a literature procedure using $\mathrm{AgClO}_{4}$ instead of $\mathrm{AgBF}_{4}{ }^{\mathrm{S} 2}{ }^{\mathrm{T}} \mathrm{The}[\mathrm{Pt}(\mathrm{tpy})(\mathrm{pic})]\left(\mathrm{BF}_{4}\right)_{2}$ was prepared according to the literature. ${ }^{\mathrm{S} 3}$

\section{Sample Preparation}

A stock solution of phosphate buffer $(\mathrm{pH}=6.95)$ was prepared using $1 \mathrm{mM}$ sodium monobasic and $1 \mathrm{mM}$ potassium dibasic solutions and $50 \mathrm{mM}$ sodium acetate. A stock solution of $30 \mathrm{mM}$ HEPES (N-[2-Hydroxyethyl] piperazine-N'-[2-ethanesulfonic acid]) buffer $(\mathrm{pH}=6.95)$ was prepared containing $100 \mathrm{mM}$ sodium acetate.

Separate stock solutions of DNA $(250 \mu \mathrm{M})$ in HEPES and phosphate buffers were prepared by combining 250 nmoles of each of the ssDNA oligos in $500 \mu \mathrm{L}$ of buffer. Single strand solutions (500 $\mu \mathrm{M}$ ) were combined, heated to $90^{\circ} \mathrm{C}$ for $2 \mathrm{~min}$, and allowed to cool to room temperature to ensure complete hybridization. Following standard procedures, the HEPES buffer solutions were used for the ITC experiments, and phosphate buffer solutions for the $\mathrm{CD}$ and melt experiments. 
Spectrophotometric titration of Pyridine Tetrapeptide with $[\operatorname{Pt}(\operatorname{tpy})]^{2+}$ : The formation of the metallated $[\mathrm{Pt}(\mathrm{tpy})(\mathrm{py})]_{4}{ }^{8+}$ tetrapeptide was monitored as previously reported ${ }^{\mathrm{S} 1}$ by UV-Visible absorption spectroscopy using a Cary $500 \mathrm{UV}-\mathrm{V}$ is NIR spectrophotometer. Briefly, a solution containing $500 \mu \mathrm{M}$ aqueous solution of the tetrapyridine oligopeptide was titrated with a stock solution of $100 \mu \mathrm{M}\left[\mathrm{Pt}(\mathrm{tpy})\left(\mathrm{CH}_{3} \mathrm{CN}\right)\right]\left(\mathrm{ClO}_{4}\right)_{2}$. Figure $\mathrm{S} 1$ shows the change in absorption during sequential additions: the inset shows that the absorption at $265 \mathrm{~nm}$ increases and levels off at a molar ratio of $4 \mathrm{Pt}^{2+}$ ions per tetrapeptide. The solution was then back-titrated to the stoichiometric equivalence point with a solution of tetrapyridine oligopeptide in water. The product was dried by lyophilization for a minimum of 48 hours prior to

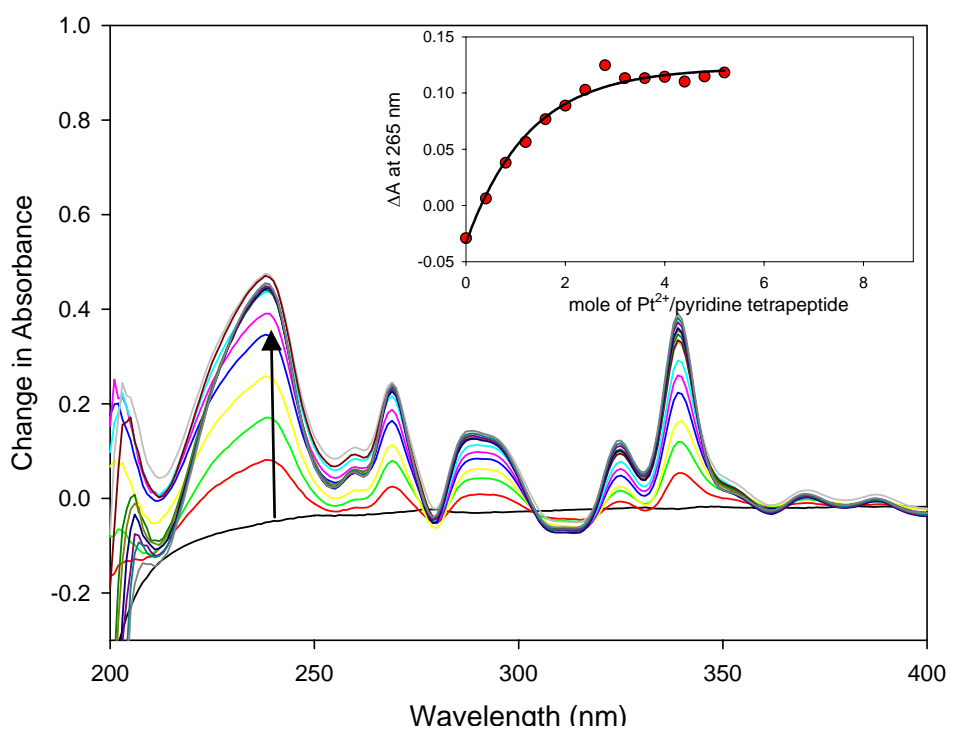

Figure S1. Difference spectra acquired during the titration of $[\mathrm{Pt}(\mathrm{tpy})]^{2+}$ with pyridine tetrapeptide. Inset: plot of the change in absorption at $265 \mathrm{~nm}$. use; purity was confirmed as before using ${ }^{1} \mathrm{H}$ NMR spectroscopy. ${ }^{\mathrm{S} 1}$

Isothermal Titration Microcalorimety (ITC): A Microcal VP-ITC isothermal titration calorimeter operating at $30^{\circ} \mathrm{C}$, a reference power of $20 \mu \mathrm{cal} / \mathrm{sec}$, and a stirring speed of $310 \mathrm{rpm}$ was used for all experiments. All solutions were prepared in $30 \mathrm{mM}$ HEPES containing $100 \mathrm{mM}$ sodium acetate. Injections of $400 \mu \mathrm{M}[\mathrm{Pt}(\mathrm{tpy})(\mathrm{py})]_{4}{ }^{8+}$ in HEPES buffer were titrated in $5 \mu \mathrm{L}$ aliquots in 10 second injection times into a $10 \mu \mathrm{M}$ DNA solution. A $200 \mathrm{sec}$ interval between injections was used to ensure a complete return to baseline after each injection. Data were corrected for background signal by performing similar titrations with buffer solutions, and fit to a single-site binding model using Origin 7 SR4, and are shown in Figure S2. Binding constants are converted to $\mathrm{M}^{-1}$ by taking the square root of the trimolecular $\mathrm{K}_{\mathrm{B}}\left(\right.$ in $\mathrm{M}^{-2}$ ). A minimum of three titrations were performed for each sample, and the fit parameters 


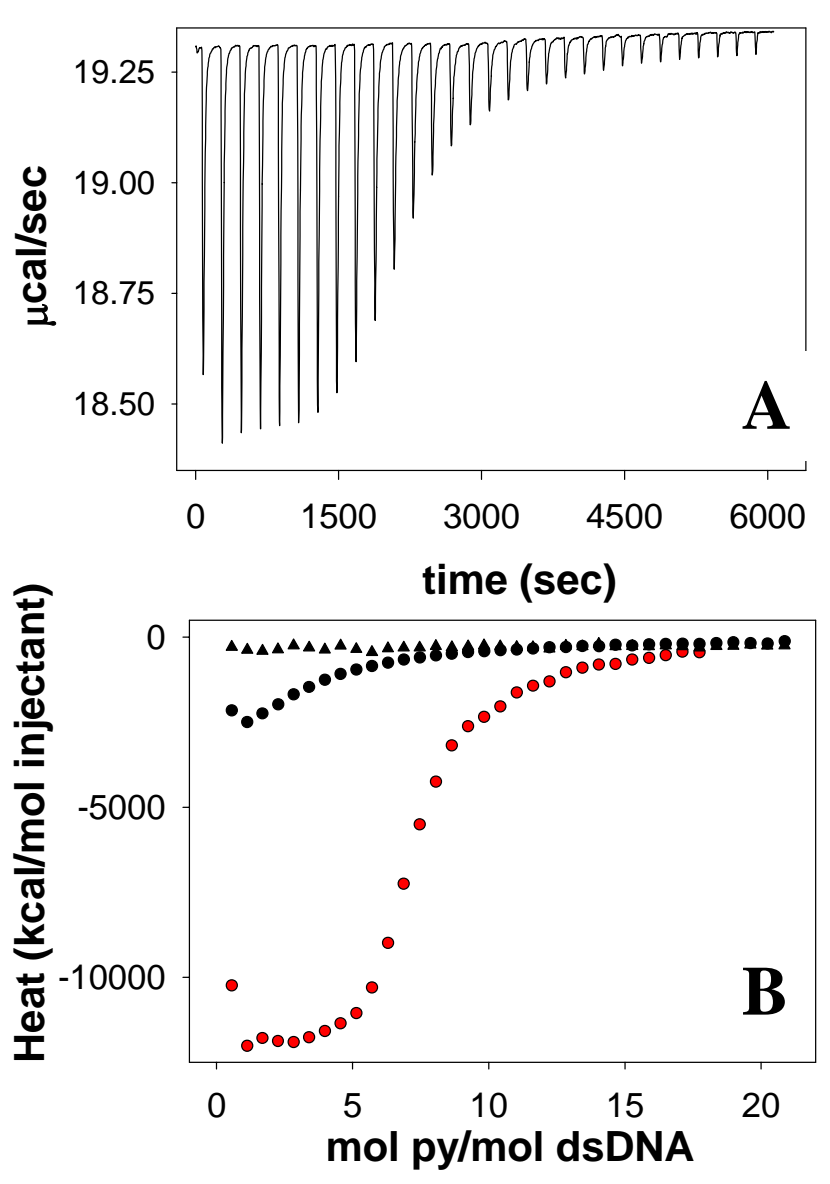

Figure S2. (A) Raw ITC data during the titration of $12 \mathrm{bp}$ dsDNA with $[\mathrm{Pt}(\mathrm{tpy})(\mathrm{py})]_{4}{ }^{{ }^{+}}$ tetrapeptide. (B) ITC curves for the titration of $12 \mathrm{bp}$ dsDNA with $[\mathrm{Pt}(\mathrm{tpy})(\mathrm{py})]_{4}{ }^{8+}$ tetrapeptide $(\mathbf{O}) ;[\operatorname{Pt}(\text { tpy })(\text { pic })]^{2+}(\mathbf{O})$; and pyridine tetrapeptide $(\boldsymbol{\Delta})$, versus the ratio of mol of pyridyl ligand/mol ds DNA. reported as the mean value \pm the standard deviation. Also shown in Figure S2 are the ITC curves for titrations performed with $400 \mu \mathrm{M}$ unmetallated pyridine tetrapeptide $(\boldsymbol{\Delta})$ solution or with a $1.6 \mathrm{mM}[\operatorname{Pt}(\mathrm{tpy})(\mathrm{pic})]^{2+}(\mathbf{O})$ solution .

Circular Dichroism (CD): All spectra were obtained using a Jasco J-810 circular dichroism spectrophotometer, a $2 \mathrm{~mm}$ cuvette, a step time of $4 \mathrm{sec}$, and a wavelength range of 400 to $205 \mathrm{~nm}$. All solutions were prepared from the phosphate buffer stock solution. Separate samples were prepared, each with $40 \mu \mathrm{M}$ dsDNA, containing molar ratios of the metallated oligopeptide to dsDNA of $0: 1,1: 0,1: 1,2: 1$, and $3: 1$.

CD Melt Spectra: Scans were obtained using a solution containing $80 \mu \mathrm{M} \quad[\mathrm{Pt}(\mathrm{tpy})(\mathrm{py})]_{4}{ }^{8+}$

tetrapeptide and $40 \mu \mathrm{M} 12 \mathrm{mer}$ DNA in phosphate buffer every two degrees heating from $25^{\circ} \mathrm{C}$ to $95^{\circ} \mathrm{C}$ and cooling back to $5^{\circ} \mathrm{C}$ on a JASCO J810 spectrophotometer. Scans were taken using a one minute holding time with a two minute equilibrium time, scanned from 370 to $210 \mathrm{~nm}$ in 4 sec integration times. Background scans using pure buffer solutions were acquired in the same cuvette, and subtracted from the initial change in ellipticity. 

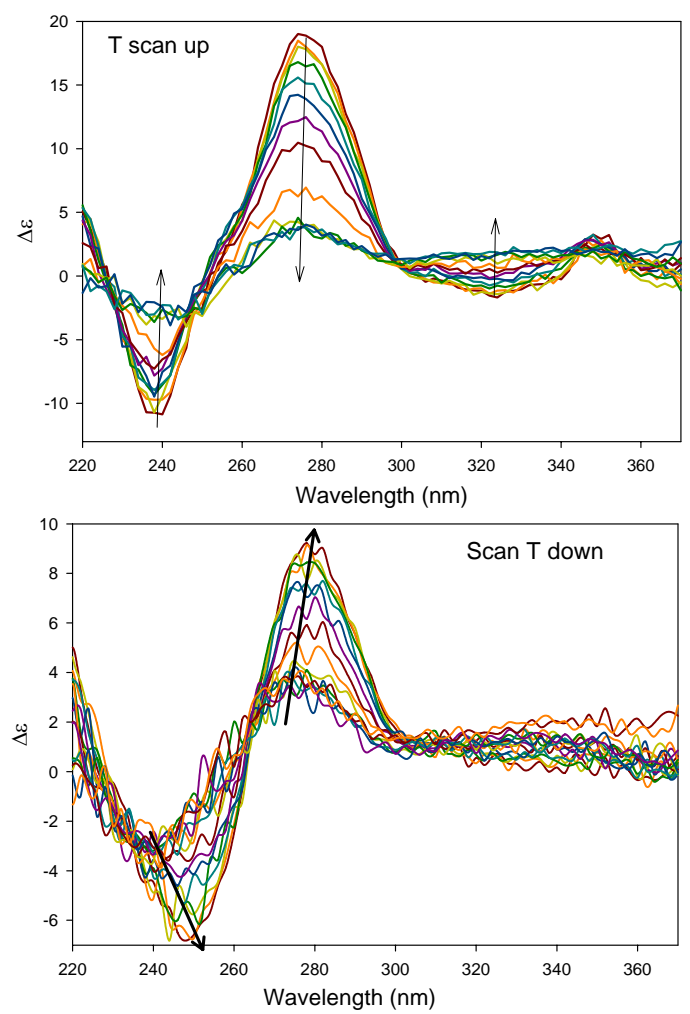

Figure S3. Temperature dependent CD spectra for a solution containing $40 \mu \mathrm{m}$ dsDNA and 80 $\mu \mathrm{m}[\mathrm{Pt}(\mathrm{tpy})(\mathrm{py})]_{4}{ }^{8+}$ tetrapeptide in phosphate buffer. Temperature was initially increased from 25 to $95^{\circ} \mathrm{C}$ (top) and then decreased from 95 to $5^{\circ} \mathrm{C}$ in $2^{\circ} \mathrm{C}$ increments.

previous literature reports; upon cooling, $\mathrm{T}_{\mathrm{m}}$ decreases to $58^{\circ} \mathrm{C}$, the same as for a solution containing only DNA.

For a sample containing 2:1 Pt tetramer:dsDNA, a second set of experiments were performed (using fresh solutions) in which the sample was heated from 30 to $95^{\circ} \mathrm{C}$, cooled to $5^{\circ} \mathrm{C}$, warmed to $30^{\circ} \mathrm{C}$ and then allowed to sit for $1-24$ hours at this temperature. Following this rest period, the absorbance data was again
UV Melts: The UV absorption at $260 \mathrm{~nm}$ was monitored as a function of temperature for each of the samples from the CD spectroscopy experiments using a Gilford Response II $\mathrm{UV}-\mathrm{Vis}$ Spectrophotometer and a $5 \mathrm{~mm}$ cuvette. Data were acquired in three sequential scans: 30 to $95^{\circ} \mathrm{C}, 95$ to $5^{\circ} \mathrm{C}$, and 5 to $95^{\circ} \mathrm{C}$. Analogous experiments were performed using a $1 \mathrm{~mm}$ cuvette with the small molecule $[\operatorname{Pt}(\text { tpy })(\text { pic })]^{2+}: 12$ mer dsDNA ratios of $1: 1,2: 1$ and $3: 1$. Melting temperatures were determined from the peaks of the derivative of the melting curves. Figure S4 shows the melting curves for the solution containing 2:1 $[\operatorname{Pt}(\text { tpy })(\text { pic })]^{2+}:$ dsDNA during sequential heating, cooling, and reheating cycles. Two inflections are observed in the initial heating cycle (at 65 and $79^{\circ} \mathrm{C}$ ), consistent with

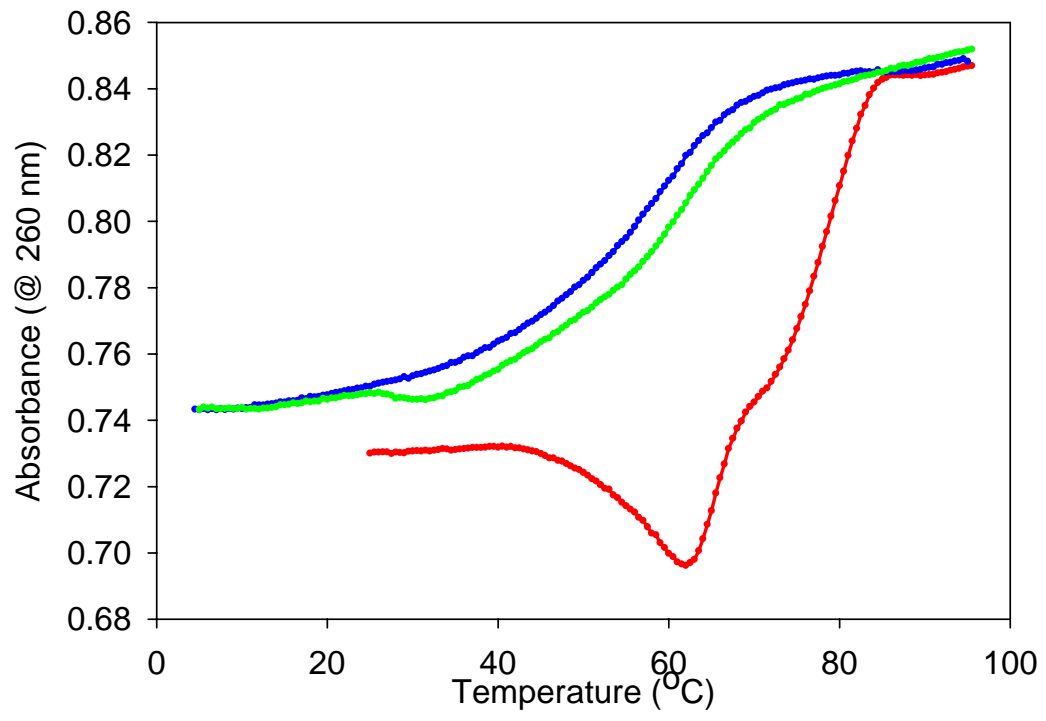

Figure S4. Temperature dependent absorption at $260 \mathrm{~nm}$ for a phosphate buffer solution containing $40 \mu \mathrm{M}$ dsDNA and $80 \mu \mathrm{M}\left[\mathrm{Pt}(\text { tpy)(pic) }]^{2+}\right.$ while heating (red), and subsequently cooling (blue line) and reheating the solution (green). 


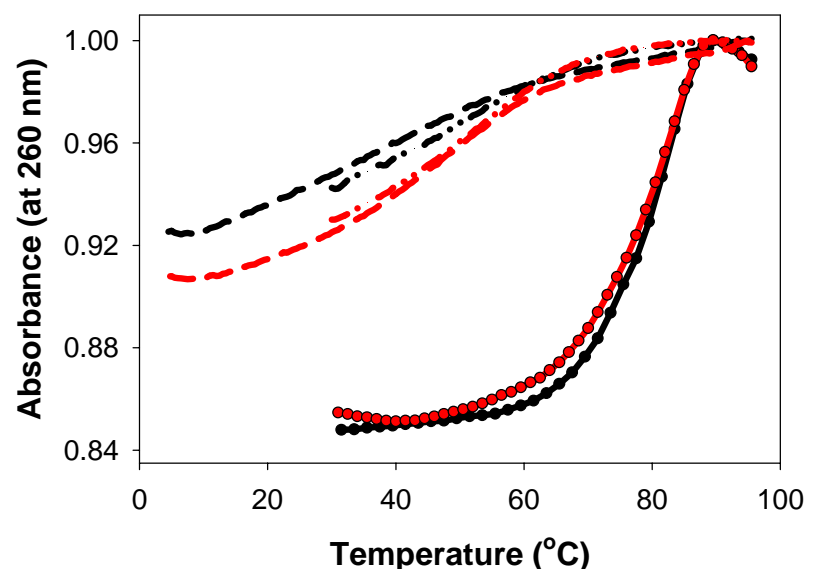

Figure S5. Temperature dependent absorption at $260 \mathrm{~nm}$ for a solution containing $40 \mu \mathrm{M}$ dsDNA and $80 \mu \mathrm{M}$ $[\mathrm{Pt}(\mathrm{tpy})(\mathrm{py})]_{4}{ }^{8+}$ (red lines) and a solution containing $40 \mu \mathrm{M}$ of each of the ssDNA oligos and $80 \mu \mathrm{M}\left[\mathrm{Pt}(\text { tpy)(py) }]_{4}{ }^{8+}\right.$ (black lines). Initial heating step $(-)$, initial cooling cycle ( - - ), and subsequent reheating cycle $(-\cdot-)$. collected over the temperature range $30-95^{\circ} \mathrm{C}$ : these data are shown in Figure S5 (red lines).

A separate experiment was performed by preparing a solution containing $80 \mu \mathrm{M}$ of the ssDNA (5'CGT GAC CAG CTG 3') and $160 \mu \mathrm{M}$ of the metallated tetrapeptide in phosphate buffer, which was allowed to sit for one hour. To this was added an equal volume of an $80 \mu \mathrm{M}$ solution of the ssDNA complement (5'GCG CTG GTC ACG3') so that the final concentration of each ssDNA oligo was $40 \mu \mathrm{M}$ and the $[\mathrm{Pt}(\mathrm{tpy})(\mathrm{py})]_{4}{ }^{8+}$ was $80 \mu \mathrm{M}$ (a 2-fold excess).

The temperature-dependent absorption was monitored as before, and the melt data is also shown in Figure S5 (black lines).

\section{Temperature Dependent Absorbance Spectra: 3D}

Melts.

All spectra were obtained using a Beckman-Coulter DU 650 over a temperature range from $25^{\circ} \mathrm{C}$ to $95^{\circ} \mathrm{C}$ and back to $25^{\circ} \mathrm{C}$, measured every $5^{\circ} \mathrm{C}$ from 370 to $220 \mathrm{~nm}$ with $0.5 \mathrm{~cm}$ cuvettes. After the cell reached the desired temperature, it was allowed to equilibrate for a minimum of 2 min. The concentration in each of the solutions of platinum terpyridine tetrapeptide was $40 \mu \mathrm{M}$. For solutions containing DNA the 12 mer concentration was $20 \mu \mathrm{M}$.

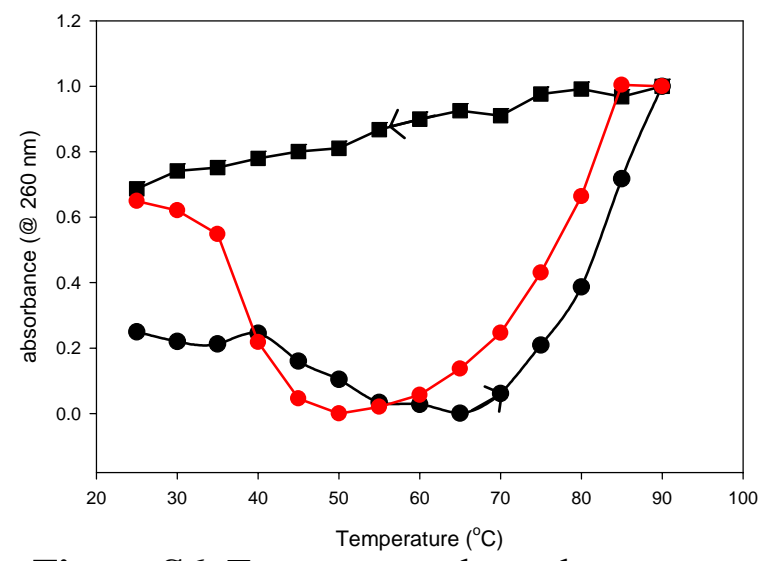

Figure S6. Temperature dependent absorbance at $260 \mathrm{~nm}$ for a solution containing $20 \mu \mathrm{M}$ DNA and $40 \mu \mathrm{M}$ $\left[\mathrm{Pt}(\text { tpy)(py) }]_{4}{ }^{8+}\right.$ while heating from 25 to $95^{\circ} \mathrm{C}(\mathbf{O})$ and subsequently cooling from 95 to $25^{\circ} \mathrm{C}(\mathbf{\square})$. An additional $6 \mathrm{~nm}$ of $[\mathrm{Pt}(\text { tpy })(\mathrm{py})]_{4}{ }^{8+}$ was added $(40 \mu \mathrm{M})$ and the absorbance again monitored while heating this solution $(O)$. 


\section{Temperature Dependent Spectra of $[\mathrm{Pt}(\mathrm{tpy})(\mathrm{py})]_{4}{ }^{8+}$}

\section{Peptide.}

Temperature dependent absorption spectra of solutions containing $50 \quad \mu \mathrm{M} \quad[\mathrm{Pt}(\mathrm{tpy})(\mathrm{py})]_{4}{ }^{8+}$ oligopeptide in both pure water and phosphate buffer stock solution were obtained with a Gilford Response II UV-Vis spectrophotometer. Scans were acquired every $5^{\circ} \mathrm{C}$ over a range of $25-95^{\circ} \mathrm{C}$, and are plotted as difference spectra (relative to the absorption at $25^{\circ} \mathrm{C}$ ) in Figure S5. Similar changes in the electronic spectra as a function of increasing temperature are observed in both solutions, likely a result coordination of water ligands. However, in phosphate buffer solutions additional peaks at lower energy are observed that are associated with acetate anions.

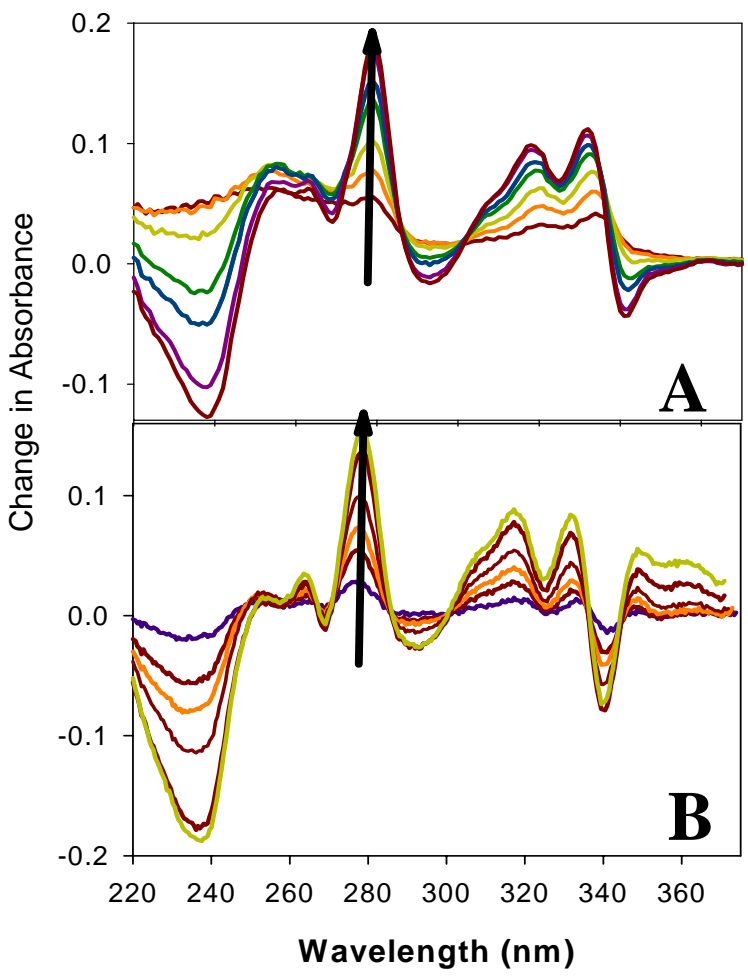

Figure S5. Change in UV absorption of $50 \mu \mathrm{M}[\mathrm{Pt}(\text { tpy })(\mathrm{py})]_{4}{ }^{8+}$ oligopeptide in (A) water and (B) phosphate buffer solutions over the temperature range $25-$ $95^{\circ} \mathrm{C}$, normalized to the absorption at $25^{\circ} \mathrm{C}$.

\section{References.}

S1 See Reference 6 in manuscript.

S2 McCoubrey, A; Latham, H. C.; Cook, P. R.; Rodger, A.; Lowe, G. FEBS Lett. 1996, 380, 73.

S3 (a) Lowe, G.; Vilaivan, T. J. Chem Research (S) 1996, 386. (b) Cusumano, M.; Di Pietro, M. L.; Giannetto, A. Inorg. Chem. 1999, 38, 1754. 